\title{
A SOCIOLINGUÚSTICA NO ENSINO DE LÍNGUAS: A VARIAÇÃ̃ DIASTRÁTICA EM MANUAIS DIDÁTICOS DE ITALIANO
}

\author{
Graziele Altino Frangiotti *
}

RESUMO: As línguas naturais são formadas por um conjunto de variedades linguísticas resultantes das intensas relações entre língua e sociedade. No ensino de línguas estrangeiras, o livro didático se constitui como uma ferramenta que tem como principal função apresentar a língua aos aprendizes. Diante dessa responsabilidade, ele não deve escamotear elementos da língua com a escusa de simplificar a aprendizagem, mas sim preparar gradativamente o aprendiz para a complexa realidade com a qual se defrontará. Com base nesse pressuposto, o presente artigo tem como finalidade investigar como os livros didáticos Rete! e Linea diretta tratam a dimensão diastrática nos diálogos e explicações oferecidas a discentes e docentes. Para isso, foram definidos 28 critérios ligados a três variedades diastráticas, a saber: o italiano popular, o italiano falado por jovens e a variedade falada por mulheres (COVERI et al., 1998). Os resultados mostram a quase total ausência dessa dimensão nos livros e o tratamento insuficiente e inadequado das três variedades.

PALAVRAS-CHAVE: Dimensão diastrática; Variedades linguísticas; Italiano popular; Italiano falado por jovens; Italiano falado por mulheres; Livro didático; Ensino de língua estrangeira.

ABSTRACT: Natural languages are formed by a set of linguistic varieties resulting from the intense relations between language and society. In teaching foreign languages, the textbook is a tool whose main function is to introduce the language to learners. Faced with this responsibility, he should not conceal elements of the language with the excuse of simplifying learning, but should gradually prepare the learner for the complex reality he will face. Based on this assumption, this article aims to investigate how the textbooks Rete! and Linea diretta deal with the diastratic dimension in the dialogues and explanations offered to students and teachers. For this, 28 criteria were defined, linked

\footnotetext{
*Universidade Federal de Santa Catarina (UFSC)

grazielefrangiotti@gmail.com

DOI: http://dx.doi.org/10.11606/issn.2238-8281.v0i38p17-38
} 
to three diastratic varieties, namely: popular Italian, Italian spoken by young people and the variety spoken by women (COVERI et al., 1998). The results show the almost total absence of this dimension in the books and the insufficient and inadequate treatment of the three varieties.

KEYWORDS: Diastratic dimension; Linguistic varieties; Popular Italian; Italian spoken by young people; Italian spoken by women; Textbook; Foreign language teaching.

ABSTRACT: Le lingue naturali sono formate da un insieme di varietà linguistiche risultanti dalle intense relazioni tra lingua e società. Nell'insegnamento delle lingue straniere, il manuale di testo è uno strumento la cui funzione principale è quella di introdurre la lingua agli studenti. Di fronte a questa responsabilità, non dovrebbe nascondere elementi del linguaggio con la scusa di semplificarne l'apprendimento, ma dovrebbe gradualmente preparare lo studente alla complessa realtà che dovrà affrontare. Sulla base di questo presupposto, questo articolo mira a indagare come i libri di testo Rete! e Linea diretta presentano la dimensione diastratica nei dialoghi e nelle spiegazioni offerte a studenti e insegnanti. A questo fine, sono stati definiti 28 criteri, collegati a tre varietà diastratiche, vale a dire: italiano popolare, italiano parlato dai giovani e varietà parlata dalle donne (COVERI et al., 1998). I risultati mostrano l'assenza quasi totale di questa dimensione nei libri e il trattamento insufficiente ed inadeguato delle tre varietà.

PAROLE CHIAVE: Dimensione diastratica; Varietà linguistiche; Italiano popolare; Italiano giovanile; Italiano al femminile; Manuale di testo; Insegnamento di lingue straniere. 


\section{Introdução}

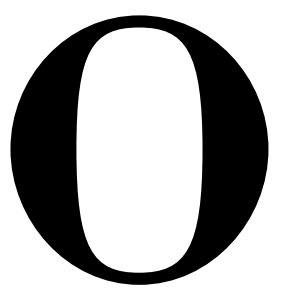

livro didático é decididamente um objeto controverso no ambiente escolar: ao mesmo tempo em que é considerado por muitos um vilão, uma vez que adota uma visão segmentada e parcial dos conteúdos escolares, é tido por outros como o conjunto que reúne tudo aquilo que os alunos devem aprender, fonte do saber acabado, inequívoco, e, portanto, incontestável.

Reiterando esses posicionamentos antagônicos, em pesquisa realizada por Coracini (1999), são identificadas duas tendências principais quanto ao emprego do livro didático: a primeira abrange os professores que fazem um uso fiel desse material, seguindo-o do início ao fim de suas aulas; enquanto a segunda abarca aqueles que o abandonam por completo, não o utilizando em momento algum.

Quanto à primeira tendência, Coracini (1999, p. 37), com base em entrevistas coletadas com professores e alunos, constata que, para os docentes que adotam apenas o livro didático, as coleções didáticas têm duas funções centrais: em primeiro lugar, são uma espécie de lembrete dos pontos previstos pelo currículo escolar que não devem ser esquecidos pelo professor; e, em segundo, atuam como um facilitador da aprendizagem, já que, segundo dizem, trazem "modelos a serem seguidos pelos alunos".

$\mathrm{Na}$ perspectiva dos aprendizes entrevistados, por outro lado, o material serve como um apoio para que eles não se percam durante as aulas, para que saibam de antemão qual será o assunto da aula e para que possam retomar os estudos em casa ou na ausência do professor. Nessa ótica, os livros didáticos são tidos como uma espécie de guia tanto da atividade docente quanto discente, além de serem avaliados pelos usuários como um propagador do modelo linguístico a ser desenvolvido em sala.

Como dissemos, há também uma segunda tendência, na qual os professores optam por banir o livro didático das aulas. Após analisar os materiais criados por esses profissionais, Coracini constata que eles acabam por criar atividades que repetem exatamente os mesmos padrões encontrados nos livros, ou seja, elaboram os mesmos tipos de perguntas em exercícios de interpretação de texto, formulam as mesmas propostas de redação e ensinam as mesmas estruturas 
gramaticais. Com isso, Coracini conclui que, ainda que não se valham de coleções didáticas, é como se o professor já tivesse internalizado os procedimentos presentes nesse tipo de material, repetindo-os mesmo a contragosto.

Para além dessas duas tendências, existe, a nosso ver, uma terceira via: aquela em que os professores escolhem utilizar o livro como alicerce para as aulas, beneficiando-se da praticidade e da economia de tempo possibilitadas por ele, mas também abrindo espaço para materiais auxiliares, muitas vezes autênticos, provenientes de outras fontes, como jornais e revistas, filmes, músicas, vídeos etc.

Levando em consideração nossa experiência em sala de aula e os diálogos tidos com outros profissionais da área de ensino de línguas estrangeiras, essa parece ser a tendência preponderante entre os professores em escolas públicas e privadas. Nesse cenário, o livro didático é empregado como um dos possíveis facilitadores da atividade docente, mas não como fonte única do insumo a ser levado à sala de aula.

Sustentamos aqui que, ainda que hoje seja comum o emprego de materiais didatizados advindos de outros suportes, o livro didático continua a ser um instrumento extremamente importante na construção do percurso escolar, sendo, portanto, imprescindível compreender não apenas sua visão de língua, mas também a amplitude e o aprofundamento através dos quais apresenta a complexidade do fenômeno linguístico.

Parte-se do pressuposto de que, se o manual didático é enxergado pelos profissionais como uma reunião dos saberes a serem desenvolvidos pelos alunos, é de se esperar que ele aborde a língua italiana em consonância com as atuais teorias linguísticas e que, assim, apresente-a como uma junção de diferentes variedades linguísticas, abarcando desde as mais prestigiadas até as mais estigmatizadas, uma vez que o aprendiz, cedo ou tarde, entrará em contato com elas, devendo estar preparado para compreendê-las e, se necessário, utilizá-las de modo adequado.

Levando em consideração esses aspectos, o presente estudo tem como objetivo observar a presença da dimensão sociolinguística em manuais didáticos de italiano e, em especial, investigar o lugar da dimensão diastrática nos livros Rete! e Linea diretta, buscando saber se e como essa dimensão é contemplada. Nos próximos parágrafos, nos deteremos na definição de diastratia, elucidaremos como esse conceito tem sido operado em estudos sociolinguísticos italianos e explanaremos a metodologia de pesquisa definida, justificando a seleção dos livros didáticos e descrevendo os procedimentos empreendidos.

\section{Diastratia: definição e variedades no contexto italiano}

De acordo com a tradição dos estudos sociolinguísticos italianos (BERRUTO, 1987, 1993, 2003; D'ACHILLE, 2006; COVERI et al., 1998; SOBRERO e MIGLIETTA, 2007, 2011; SANTIPOLO, 2002; TORQUATO, 2011), a variação linguística possui algumas dimensões fundamentais, como a diacronia, a diatopia, a diamesia, a diafasia e a diastratia.

A dimensão diacrônica se relaciona às alterações sofridas pela língua quando comparados 
dois momentos distintos de seu desenvolvimento. É essa dimensão que está envolvida, por exemplo, quando constatamos o desuso na língua comum de termos italianos como cagione e favellare, hoje preteridos em favor, respectivamente, de ragione (razão) e parlare (falar).

Já a diatopia é identificada a partir da comparação de produções linguísticas de falantes provenientes de diferentes áreas geográficas. Ela pode perpassar desde aspectos puramente lexicais, como a diferença de distribuição dos termos cocomero e anguria (melancia), utilizados, respectivamente, no centro e no centro-sul da Itália (COVERI et al., 1998, p. 55); até aspectos morfossintáticos e fonológicos.

A diamesia, por sua vez, refere-se às diferenças causadas pelo meio empregado para a interação. Assim, envolve fenômenos capazes de distinguir a oralidade da escrita, como o emprego de sinais discursivos (allora, quindi, cioè, vabbé); a utilização de termos genéricos (cosa, tipo) e a repetição de conjunções de uso frequente (perché, però, se e poiché).

As variedades diafásicas são aquelas relativas ao contexto social no qual se insere um dado evento comunicativo, estando vinculadas, sobretudo, à relação estabelecida entre os interlocutores. Essa dimensão pode ser exemplificada por expressões como mi sa (me parece) ou quagliare (ter êxito positivo, concluir), empregadas em contextos informais, tendo como equivalentes mais formais, respectivamente, mi sembra e concludersi.

A variação diastrática, foco desta investigação, é aquela que pressupõe a existência de diferentes grupos sociais em uma comunidade linguística. Nessa dimensão, situam-se as variedades ligadas ao grau de instrução, à idade e ao sexo dos indivíduos.

Em contexto italiano, estudiosos como Coveri et al. (1998), assim como Sobrero e Miglietta (2007), arrolam nessa dimensão as seguintes variedades: o italiano culto; o italiano popular; o italiano falado por jovens e o italiano falado por homens e mulheres.

Para esses autores, o italiano culto constitui o italiano falado por aqueles cujo nível de instrução é médio-alto ou alto. Segundo afirmam Coveri et al. (1998, p. 98), o italiano culto não foi suficientemente descrito, sendo tomado comumente como uma variedade cujos traços coincidem grosso modo com o italiano padrão. A nosso ver, essa equivalência entre variedade culta e padrão não deve ser estabelecida a priori, uma vez que estudos como os do projeto Norma Urbana Culta (NURC), dedicado à análise do português em capitais brasileiras, evidenciaram justamente o oposto: que a língua falada por indivíduos com alto grau de instrução em situações menos formais se distancia em vários pontos do português normativo, aproximando-se consideravelmente do falar das camadas menos escolarizadas. Assim, em virtude de não conhecermos trabalhos em que se reflita de modo mais aprofundado sobre o tema, optamos por excluir essa variedade do estudo.

A noção de italiano popular nasce no início da década de 1970, introduzida por Tullio De Mauro (1970) e, logo em seguida, por Manlio Cortelazzo (1972). Para De Mauro, o italiano popular constitui "il modo d'esprimersi di un incolto che, sotto la spinta di comunicare e senza addestramento, maneggia quella che ottimisticamente si chiama la lingua nazionale” (1970, p. 
49) ${ }^{1}$, já para Cortelazzo (1972, p. 11), o italiano popular é "il tipo di italiano imperfettamente acquisito da chi ha per madrelingua il dialetto"2.

Mais tarde, a fim de dirimir imprecisões e de fundir essas duas visões teóricas, Berruto definirá a variedade da seguinte maneira:

quell'insieme di usi frequentemente ricorrenti nel parlare e (quando sia il caso) nello scrivere di persone non istruite e che per lo più nella vita quotidiana usano il dialetto, caratterizzati da numerose devianze rispetto a quanto previsto dall'italiano standard. $\left(1993\right.$, p. 58) ${ }^{3}$

Ao longo de mais de duas décadas, entre os anos de 1970 e 1990, os estudos centrados na variedade popular ocuparam lugar de destaque na Sociolinguística italiana. Entre outras coisas, foram desenvolvidas análises construídas a partir de cartas enviadas por soldados durante a Primeira Guerra Mundial (cf. Spitzer, 1922), através das quais foi possível diagnosticar a influência da língua materna do emissor - um dos dialetos itálicos - na formação da variedade popular, enquanto o italiano língua nacional, nesse contexto, atuava como uma espécie de segunda língua, adquirida apenas em contexto de instrução formal e, quase sempre, de forma insuficiente, tendo em vista o baixo nível de escolaridade alcançado pelos indivíduos nesse período. A variedade popular consolida-se, assim, como a língua empregada por dialetófonos que detêm conhecimento fragmentário do italiano.

Em texto de 2014, Berruto revisita o conceito de italiano popular, afirmando que haveria linguistas que estariam alegando o desaparecimento da variedade nos dias atuais. Para Berruto, a perda de potência da noção de italiano popular se dá em virtude de duas correntes argumentativas: a primeira alega que a variedade popular deixou de existir em decorrência do aumento da escolarização dos italianos, que fez com que houvesse a diminuição da dialetofonia e a consequente diminuição do número de indivíduos que tinham por única língua o dialeto ${ }^{4}$; enquanto a segunda sustenta que os fenômenos tidos como característicos do italiano popular, na realidade, nada mais são que traços das variedades informais, não relacionadas, portanto, ao grau de instrução dos usuários da língua, mas sim ao contexto de interação.

No artigo, o linguista italiano se esforçará para demonstrar:

(a) che l'italiano popolare, in una caratterizzazione del tutto simile se non identica a quella che è stata ampiamente schizzata per il passato, esiste tuttora tra gli usi presenti nel panorama dell'italiano contemporaneo: anche all'inizio del terzo millennio c'è chi parla e scrive in

1 "Modo de se exprimir de um inculto que, diante da necessidade de se comunicar e sem prática, manipula aquela que de forma otimista é denominada língua nacional." (todas as traduções de textos italianos são de nossa autoria).

2 "O tipo de italiano imperfeitamente adquirido por quem tem como língua materna o dialeto."

3 "Aquele conjunto de usos frequentemente recorrentes na fala e (quando for o caso) na escrita de pessoas não instruídas e que na maioria das vezes na vida cotidiana usam o dialeto, caracterizados por numerosos desvios com relação ao previsto pelo italiano standard normativo."

4 Acerca das políticas linguísticas implementadas em território italiano, o artigo de Lunati, Balthazar e Freitas (2015) demonstra como diferentes governos e partidos políticos enxergaram a convivência entre língua e dialetos desde a Unificação italiana até a atualidade. Retomando leis, desenhos de leis, decretos e programas escolares, as autoras mostram como na Itália não houve nenhuma sistematicidade nas políticas para a educação linguística, principalmente no tocante ao ensino dos dialetos, que foram vistos ora como "pragas" a serem evitadas, ora como patrimônio linguístico-cultural a ser valorizado no contexto escolar. 
italiano popolare; e (b) che vi è un insieme di tratti linguistici che differenziano e identificano l'italiano popolare come varietà di lingua (BERRUTO, 2014, p. 278) ${ }^{5}$

Para fazê-lo, o estudioso recorre a exemplos retirados da escrita e da produção oral de falantes pouco escolarizados, chegando à conclusão, em concordância com Mocciaro (2011), que o italiano popular hoje "appare tipico, se non esclusivo, di parlanti anziani" ${ }^{\circ}$. Em suas palavras, o italiano popular estaria então destinado a desaparecer, em um processo de extinção linguística, fenômeno certamente muito interessante, mas que estaria sendo totalmente negligenciado no campo científico.

Embora o italiano popular seja de difícil caracterização devido aos inúmeros dialetos existentes na Itália, pesquisas fornecem um elenco de elementos que compareceriam independentemente da origem do falante. Coveri et al. os listam:

Quadro 1: Características do italiano popular

\begin{tabular}{|c|c|}
\hline 1. acúmulo de preposições; & "Lavora presso a delle famiglie" \\
\hline 2. acusativo preposicionado; & "A me non mi mandi li" \\
\hline $\begin{array}{l}\text { 3. adjetivo invariável usado com função } \\
\text { adverbial; }\end{array}$ & $\begin{array}{l}\text { "Gli voglio bene uguale" por } \\
\text { "ugualmente" }\end{array}$ \\
\hline 4. cancelamento de morfemas; & "dichiara" por "dichiarazione"; \\
\hline 5. cancelamento de sílabas; & "dirizzo" por "indirizzo" \\
\hline $\begin{array}{l}\text { 6. concordância morfológica com base no } \\
\text { significado; }\end{array}$ & "La coppia ballano" \\
\hline 7. expressões hiper-caracterizadas; & "la più maggiore" por "la maggiore" \\
\hline $\begin{array}{l}\text { 8. grafia que provém da pronúncia e } \\
\text { divisão errada das palavras; }\end{array}$ & "falzo" por "falso" e "avvoi" por "a voi" \\
\hline 9. paraetimologia; & "autobilancia" por "autoambulanza"; \\
\hline 10. simplificação de nexos consonânticos; & "tennico" por "técnico" \\
\hline $\begin{array}{l}\text { 11. simplificação do paradigma dos } \\
\text { pronomes possessivos; }\end{array}$ & $\begin{array}{l}\text { "Conosci Francesca e Paolo? Ho visitato la } \\
\text { casa sua." por "Conosci Francesca e Paolo? } \\
\text { Ho visitato la loro casa." }\end{array}$ \\
\hline 12. uso de frases prontas. & $\begin{array}{l}\text { "indisponibilità di tempo", "con ciò mi } \\
\text { congedo" }\end{array}$ \\
\hline
\end{tabular}

Fonte: Adaptado de Coveri et al. (1998, p. 97)

5 “a) que o italiano popular, em uma caracterização totalmente similar se não idêntica àquela que foi amplamente delineada no passado, existe ainda hoje entre os usos presentes no panorama do italiano contemporâneo: mesmo no início do terceiro milênio existe quem fala e escreve em italiano popular; b) que existe um conjunto de traços linguísticos que diferenciam e identificam o italiano popular como variedade de língua."

6 "o italiano popular parece típico, se não exclusivo, de falantes idosos". Berruto (2014) dá exemplos de produções orais com traços de italiano popular realizadas por falantes jovens, netos e bisnetos de falantes da variedade. Nesses casos, trata-se de um uso que visa à convergência interacional, isto é, os jovens empregam certas formas linguísticas para se aproximarem da maneira de falar de seus avós quando estão se dirigindo a eles. No entanto, nas palavras de Berruto, seriam necessários exames mais aprofundados dessas interações para que se chegue a conclusões mais significativas. 
A segunda variedade associada à diastratia, o italiano falado por jovens, é utilizada por indivíduos que estão passando da adolescência à idade adulta, compreendendo normalmente a faixa etária de 14 a 21 anos.

Em contexto italiano, segundo Marano (2010), a variedade falada pelos jovens seria nutrida por uma tensão entre um polo lexical internacional - com estrangeirismos usados principalmente para efeito cômico/jocoso - e uma dimensão provincial de tipo dialetal. Esse último traço aproximaria o italiano falado por jovens à dimensão diatópica, pois, como evidenciado nas análises de Alfonzetti (2001), na linguagem utilizada por adolescentes são extremamente recorrentes code-switchings, isto é, alternâncias de código entre a língua nacional e um dos dialetos falados na península.

O italiano falado por jovens é normalmente empregado em contextos específicos, quando jovens interagem com seus pares em ambientes como a escola (fora e, às vezes, dentro da sala de aula), em cursos que frequentam, na casa de amigos e em locais de trabalho ou lazer.

Para Sobrero e Miglietta (2007, p. 105), essa variedade é composta por seis camadas linguísticas: italiano coloquial informal, dialeto, gírias tradicionais, gírias inovadoras, linguagem da publicidade e dos meios de comunicação e línguas estrangeiras. A variedade é fortemente atrelada ao plano lexical da língua, embora também possa apresentar traços relativos à morfossintaxe, por exemplo. No entanto, em conformidade com Radtke (1993) e Cortelazzo (1994), é impossível falar de uma sintaxe ou de uma morfologia própria da língua juvenil, logo, o campo lexical surge como aquele que a caracteriza mais fortemente.

Dada essa confluência de fontes linguísticas, o italiano dos jovens é um conjunto de usos marcados através das gerações e da área geográfica de proveniência de seus falantes, que tem como característica principal a rápida atualização de seus elementos constituintes, velocidade essa que inviabiliza ou ao menos dificulta a realização de estudos nessa área ${ }^{7}$. No que tange à sua função, ele é empregado para causar efeito lúdico, reforçar a coesão de grupo e para evidenciar a contraposição com relação a outros grupos. Sobre o efeito lúdico, Sobrero e Miglietta afirmam:

[...] il carattere specifico delle varietà giovanili è il gioco, che è del tutto secondario nei gerghi. La 'stranezza' e 'l'incomprensibilità' fanno parte del gioco, anzi sono subordinate a quella che sembra la funzione prevalente: la funzione ludica $(2007, \text { p. } 105)^{8}$

Segundo Coveri et al. (1998), os fenômenos típicos dessa variedade são9:

$7 \quad$ Na tentativa de acompanhar a velocidade com que o italiano dos jovens se modifica, Maria Simonetti é responsável pelo dicionário online Slangopedia, cuja finalidade é apresentar novas palavras do italiano dos jovens. Falantes de diferentes regiões enviam mensagens à redação do jornal L'Espresso informando o significado e a área de proveniência de termos ainda não presentes no dicionário. A cada duas semanas, o dicionário, hospedado no site desse jornal, é ampliado graças às indicações feitas pelos leitores. Disponível em: http://temi.repubblica.it/espresso-slangopedia. Acesso em 16 jan. 2020.

8 " "...] a característica específica das variedades dos jovens é o jogo, que é completamente secundário nas gírias. O ‘estranhamento’ e a ‘incompreensibilidade’ fazem parte do jogo, aliás são subordinados àquela que parece ser a função prevalente: a função lúdica."

9 Outros estudos sobre esse tema são de Banfi (1992); Banfi e Sobrero (1992); Radtke (1993, 2005); Montuori (2006); Colella (2008), entre outros. 
Quadro 2: Características do italiano falado por jovens

\begin{tabular}{|c|c|}
\hline 1. abreviações & "mega" por "grande" \\
\hline 2. dialetismos & "pirla" do milanês, que significa "stupido" \\
\hline 3. estrangeirismos & "new entry" por "studente appena arrivato" \\
\hline $\begin{array}{l}\text { 4. eufemismos com efeito cômico/ } \\
\text { irônico }\end{array}$ & "lattiginoso" por "pallido come un cadavere" \\
\hline \begin{tabular}{|l} 
5. \\
$\begin{array}{l}\text { expressões cultas usadas } \\
\text { informalmente para efeito irônico } \\
\text { ou cômico }\end{array}$ \\
\end{tabular} & "omaggiare" por "regalare" \\
\hline 6. gírias & "secchione" por "studente che studia molto" \\
\hline 7. hipérbole & "mítico" por "bello, bravo" \\
\hline 8. turpilóquios & "un cazzo" por "un niente", "palle" por "noia" \\
\hline 9. metáfora & "un cesso" por "brutto" \\
\hline 10. metátese & "drema" por "madre" \\
\hline 11. sufixos raros & $\begin{array}{l}\text { “-ozzo", como em "paninozzo", que significa } \\
\text { "panino" }\end{array}$ \\
\hline 12. tecnicismos & "cerebroleso" por "stupido" \\
\hline
\end{tabular}

Fonte: Coveri et al. (1998, p. 104)

Além das variedades relativas ao nível de instrução e à idade, existem ainda as variedades influenciadas pelo gênero dos falantes. As diferenças entre a variedade feminina e masculina começaram a ser estudadas na década de 1970, principalmente por Lakoff (1975) na obra Language and woman's place.

À época, o estudioso conduziu sua pesquisa e chegou a duas conclusões fundamentais: a primeira era que as mulheres tendiam a ser linguisticamente mais conservadoras que os homens devido ao fato de passarem a maior parte do tempo em casa e alheias às mudanças linguísticas. A segunda era que elas usavam as variantes consideradas de maior prestígio, o que ocorria, nas palavras desse estudioso, em virtude de elas serem as condutoras da educação dos filhos, fato que as levava a preferir as formas mais aceitas socialmente.

A partir desse estudo, pôde-se começar a notar que existiam diferenças relevantes entre a língua falada por homens e mulheres e a perceber que essas diferenças dependiam da posição que os indivíduos ocupavam na sociedade. Logo, foi se tornando cada vez mais evidente a importância de se conhecerem as atividades, os papéis sociais e os meios nos quais circulam homens e mulheres para uma análise mais produtiva dos traços característicos de suas produções linguísticas. 
Na Itália, nas últimas décadas, os movimentos feministas têm reivindicado um uso não sexista da língua, incentivando, entre outras coisas, a formação e o uso de novas palavras que designem as profissões que anteriormente eram exercidas apenas por homens. Esses grupos exigem também o abandono do acordo morfológico que respeita o gênero masculino mesmo nas situações nas quais o número de homens é menor que o número de mulheres e lutam pelo redimensionamento do lugar ocupado pelas mulheres também no âmbito das atitudes e preconceitos linguísticos.

Infelizmente, ainda nos dias de hoje, é bastante comum no panorama dos estudos italianos, o enfoque de que a variedade masculina seria "neutra", tomada como ponto de referência para o exame daquela que seria a variedade marcada, não neutra, isto é, a variedade feminina. Nos opomos a essa perspectiva que coloca a variedade feminina como subalterna em relação à masculina e também à divisão simplória e de caráter heterossexual que considera somente o falar de homens e mulheres. Pensamos que seja importante e urgente a ampliação e a atualização da discussão, introduzindo as reflexões mais recentes sobre gêneros e sexualidade, no entanto, para as discussões deste trabalho, nos apoiaremos em Coveri et al. (1998), pelo fato de os autores proporem um elenco com alguns fenômenos que seriam atinentes à variedade falada por mulheres:

Quadro 3: Características da variedade falada por mulheres

\begin{tabular}{|l|l|}
\hline 1. apelativos afetuosos & tesoro, amore, ciccina, gattina \\
\hline 2. uso frequente de diminutivos & fratellino, piccolino, piantina \\
\hline 3. hipérboles & ripetere un milione di volte, salire alle stelle \\
\hline $\begin{array}{l}\text { 4. uso pouco frequente de palavras } \\
\text { tabu }\end{array}$ & vecchio (persona), grasso, pene, vagina \\
\hline
\end{tabular}

Fonte: Adaptado de Coveri et al. (1998, p. 106-7)

Apresentadas as características das variedades focalizadas neste estudo, surge o questionamento se os aprendizes de italiano deveriam, de fato, ser expostos a tais fenômenos, posto que alguns desses aspectos, sobretudo aqueles ligados à variedade popular, vão de encontro aos conteúdos gramaticais normalmente incluídos no currículo de ensino dessa língua. Se poderá questionar se seria realmente importante que fossem ensinadas formas que, na perspectiva da gramática normativa, são tidas como "erros".

Para responder a essas indagações, partimos do princípio de que os aprendizes de língua estrangeira devem ser expostos à língua efetivamente encontrada nas localidades onde é falada. Assim, nos parece equivocada a decisão de simplificá-la demasiadamente em sala de aula, dado que tais simplificações podem acarretar em distorções artificiais que poderão comprometer a 
atuação dos aprendizes.

Desse ponto de vista, se a língua italiana possui diferentes variedades linguísticas, não há razão para que se fuja a essa realidade. Além disso, acreditamos que, mais que preparar os alunos para memorizar ou para ser capaz de compreender e/ou produzir cada um dos fenômenos dessas variedades, as discussões em sala devam ser conduzidas com vistas a conscientizá-los de que o italiano não é um sistema fixo e imutável e de que os falantes dessa língua não a produzem todos da mesma maneira.

Espera-se, portanto, que discussões sobre estigma e prestígio linguísticos sejam paulatinamente introduzidas e que, inclusive, sejam estabelecidas comparações entre a língua italiana e a língua materna dos alunos, no caso o português, para que sejam debatidos possíveis pontos de convergência e divergência entre as línguas, promovendo o aumento do grau de sensibilidade sociolinguística dos aprendizes.

\section{O estudo: seleção dos livros e procedimentos de análise}

Para a implementação da investigação, foram selecionados dois livros didáticos: Linea diretta (doravante LD) e Rete! (doravante R!), escolhidos com base em estudo preliminar realizado através de questionário enviado a vinte escolas de idiomas paulistas, a partir do qual se detectou a preponderância de uso dessas coleções no ensino da língua italiana no estado de São Paulo.

A coleção Linea Diretta foi escrita por Corrado Conforti e Linda Cusimano. A primeira edição foi publicada na Alemanha em 1994 e era constituída de dois volumes de livros do aluno, dois volumes de livros de exercícios, dois cd-áudio e dois manuais do professor, um para cada volume do livro. Em 2005, o primeiro volume foi dividido em Linea Diretta nuovo la e Linea diretta $1 b$ (doravante LD1a e LD1b). Com essa alteração, os livros de exercícios, que eram vendidos em um volume separado, passaram a integrar os dois volumes de livro do aluno e apenas o Linea Diretta 2 (doravante LD2) continuou com a mesma formatação, com o livro de exercícios vendido separadamente. A coleção é estruturada em 31 unidades didáticas distribuídas da seguinte maneira: oito lições em LD1a, oito lições em LD1b e quinze lições em LD2.

O manual Rete! foi primeiramente publicado em 2000 e nasceu, segundo os seus autores, Marco Mezzadri e Paolo Balboni, da intersecção de três diretrizes: 1. a tradição didática italiana, presente no livro através da organização das lições como unidades monotemáticas e da presença de atividades que oferecem largo espaço para a cultura do país; 2. a contribuição do Conselho da Europa, na medida em que ele estabelece na Comunidade Europeia os níveis a serem percorridos pelos aprendizes; 3 . a pesquisa em ensino de línguas, com suas contribuições no que se refere à abordagem indutiva da gramática, à igual dignidade entre forma e aspectos da capacidade pragmática, à importância da autoavaliação, entre outros.

A coleção é formada por três volumes: Rete!1 (doravante R!1), Rete!2 (doravante R!2) e Rete!3 (doravante R!3). A cada volume do livro do aluno trabalhado em sala de aula, corres- 
ponde um livro de casa, destinado ao estudo individual. A coleção conta ainda com cd-áudio, que contêm alguns dos diálogos presentes no livro do aluno, e com o guia do professor. Quanto à estrutura, $\mathrm{R}$ !1 e R!2 trazem quinze unidades didáticas cada um, enquanto $\mathrm{R}$ !3 é formado por dez. Com isso, a série de livros é composta por 40 unidades a serem trabalhadas em cerca de 300 horas (número sugerido pelos autores).

No que concerne aos procedimentos analíticos empreendidos, foi definido que o exame dos manuais se concentraria na seção de diálogos, uma vez que percebemos que ela era o núcleo a partir do qual toda a sequência didática se organizava, sendo assim, se houvesse alguma preocupação em incorporar fenômenos marcados sociolinguisticamente, eles provavelmente seriam introduzidos nessa seção.

Além disso, foram examinadas todas as páginas das coleções, tanto dos livros do aluno quanto dos de exercícios e os guias do professor, com o objetivo de evidenciar referências explícitas às variedades linguísticas ou aos fenômenos estudados.

Como critério para as análises dos diálogos, nos baseamos em bibliografia pertinente (COVERI et al., 1998) e elaboramos os elencos de fenômenos descritos no parágrafo anterior. Em seguida, procuramos doze fenômenos relativos à variedade popular, doze referentes ao italiano falado por jovens e quatro ao italiano falado por mulheres, totalizando 28 critérios.

\section{Resultados: há espaço para a diastratia nos livros didáticos?}

Ao término da análise, foram observados 103 diálogos, desse total 35 contidos no LD e 68 no livro R!. O primeiro conjunto de traços examinados fez emergir um completo silenciamento da variedade popular nas duas coleções. A tabela a seguir mostra os resultados obtidos na busca de aspectos dessa variedade: 
Tabela 1: Resultados italiano popular

\begin{tabular}{|l|c|c|c|c|c|c|}
\hline \multicolumn{1}{|c|}{ Traço investigado } & LD1a & LD1b & LD2 & R!1 & R!2 & R!3 \\
\hline acúmulo de preposições & 0 & 0 & 0 & 0 & 0 & 0 \\
\hline acusativo preposicionado & 0 & 0 & 1 & 0 & 0 & 0 \\
\hline $\begin{array}{l}\text { adjetivo invariável usado com função } \\
\text { adverbial }\end{array}$ & 0 & 0 & 0 & 1 & 0 & 0 \\
\hline cancelamento de morfemas & 0 & 0 & 0 & 0 & 0 & 0 \\
\hline cancelamento de sílabas & 0 & 0 & 0 & 0 & 0 & 0 \\
\hline $\begin{array}{l}\text { concordância morfológica com base } \\
\text { no significado }\end{array}$ & 0 & 0 & 0 & 0 & 0 & 0 \\
\hline expressões hiper-caracterizadas & 0 & 0 & 0 & 0 & 0 & 0 \\
\hline $\begin{array}{l}\text { grafia que provém da pronúncia e divi- } \\
\text { são errada das palavras }\end{array}$ & 0 & 0 & 0 & 0 & 0 & 0 \\
\hline paraetimologia & 0 & 0 & 0 & 0 & 0 & 0 \\
\hline simplificação de nexos consonânticos & 0 & 0 & 0 & 0 & 0 & 0 \\
\hline $\begin{array}{l}\text { simplificação do paradigma dos } \\
\text { pronomes possessivos }\end{array}$ & 0 & 0 & 0 & 0 & 0 & 0 \\
\hline uso de frases prontas & 0 & 0 & 0 & 0 & 0 & 0 \\
\hline
\end{tabular}

Como mostram os números contidos na tabela, não foram coletadas muitas ocorrências de fenômenos do italiano popular. Além disso, quando uma determinada característica foi detectada, como no caso de "acusativo preposicionado" ou "adjetivo invariável utilizado com função adverbial" isso se deu em apenas um diálogo, gerando percentuais finais extremamente baixos.

A ocorrência do acusativo preposicionado foi detectada na última unidade do LD2 e constitui uma interação entre dois amigos que debatem o uso de estrangeirismos, principalmente de origem inglesa, na língua italiana. A certo ponto da discussão, um dos personagens diz: "non ti si convince neanche a te" (não se convence nem a você) e emprega como complemento do verbo transitivo direto convincere um objeto preposicionado: $a$ te.

Assim que nos deparamos com essa construção, supomos não se tratar de um exemplo de italiano popular, pois tanto do ponto de vista da temática quanto das estruturas da língua italiana usadas seria pouco provável que esses personagens tenham sido construídos para representar o falar de pessoas com baixo nível de escolaridade.

Reiterando essa hipótese, D’Achille (2006, p. 183), falando do acusativo preposicionado, expõe que em muitos dialetos italianos centro-meridionais, bem como nas correspondentes 
variedades regionais, esse é um construto bastante difundido. Em seguida, especifica que com alguns verbos como convincere [convencer], invitare [convidar], consolare [consolar], divertire [divertir], preoccupare [preocupar], spaventare [assustar] esse fenômeno "non ha più di fatto, delimitazioni areali, ma è panitaliano, diffuso anche in varietà parlate non popolari né regionali" ${ }^{10}$, o que comprova que a ocorrência identificada no livro didático não permite dizer que há exposição dos aprendizes a traços tipicamente populares.

Também quanto à presença do critério "adjetivo invariável no lugar de advérbio" não é possível afirmar com certeza que a personagem que o produz seja um falante da variedade popular, pois, similarmente à situação anterior, não são oferecidos dados sobre o seu nível de instrução, tampouco sobre o seu vínculo com o dialeto. Além disso, a produção respeita na sua quase totalidade a norma padrão italiana, portanto a presença desse aspecto nos parece forte indício de que esse fenômeno perpassa outras variedades linguísticas.

No que tange à segunda etapa da pesquisa: a análise das atividades e das instruções contidas nos seis volumes, confirmou-se a quase completa exclusão da variedade popular como objeto de ensino, já que no LD ela não foi tratada explicitamente, enquanto no R! foi encontrada em apenas dois comentários.

O primeiro comentário refere-se a uma passagem encontrada no livro de classe do terceiro volume da série R!, na qual se focaliza o uso da expressão "c'ho azzeccato", parafraseada como "un modo più popolare di dire indovinare" (um modo mais popular de dizer adivinhar), (p. 81). É necessário esclarecer, contudo, que aqui o termo "popular" parece não coincidir com a definição utilizada neste trabalho, pois nos dicionários de língua italiana não encontramos registros que indiquem qualquer relação da expressão "azzeccarci" com a diastratia.

Nessa direção, o dicionário Garzanti linguistica, por exemplo, define-a apenas como: "indovinare; trovare la risposta o la soluzione giusta: azzeccò la risposta al primo colpo; non riesco mai ad azzeccare il momento giusto" ", e não insere antes da definição nenhum tipo de abreviação que sugira um contexto de uso particular.

Já no dicionário Sabatini Coletti, sua definição é: “colpire qualcosa nel segno, nel punto giusto, specialmente in senso figurato, indovinare qualcosa per caso: azzeccare la risposta esatta // fam. non azzeccarne mai una, non fare mai la cosa opportuna" ${ }^{12}$. Como fica claro pela abreviação utilizada - "fam." -, poderia-se atribuir a essa expressão, no máximo, um uso familiar, não formal, mas não popular no sentido técnico atribuído pelos sociolinguistas.

O segundo trecho identificado está presente na unidade 11 do segundo volume do guia do professor da série R!:

[...] nell'italiano popolare la consecutio temporum, cioè la concatenazione sintattica tra i tempi e i modi, è spesso molto intuitiva ed è qui che si registrano i maggiori ‘errori’; quando scrivono, gli italiani che di solito parlano italiano

10 “não tem mais, de fato, delimitações de área, mas é 'panitaliano’, difundido também em variedades faladas não populares nem regionais"

11 "adivinhar; encontrar a resposta ou a solução correta: adivinhou a resposta no primeiro chute; nunca consigo adivinhar no momento correto". Disponível em: <http://www.garzantilinguistica.it/ricerca/?q=azzeccare>. Acesso em 22 jan. 2020.

12 "atingir algo no alvo, no ponto correto, especialmente em sentido figurado, adivinhar algo por acaso: adivinhar a resposta exata // fam. Não dar uma dentro, nunca fazer a coisa oportuna”. Disponível em: < https://dizionari. corriere.it/dizionario_italiano/A/azzeccare.shtml>. Acesso em 22 de jan. 2020. 
popolare tendono all'ipercorrettismo, cioè a dare parvenza di 'nobiltà' al loro scritto - e questa nobiltà viene dall'abuso dei vari tempi del passato, che soprattutto al condizionale e al congiuntivo vengono spesso confusi, con risultati spesso grotteschi. (R!2: GP, p. 132) ${ }^{13}$

O fato de o livro incluir a informação de que há no italiano popular uma concatenação sintática muito intuitiva nos parece positivo, na medida em que demonstra que está atualizado com relação à situação linguística italiana. Por outro lado, a maneira como os autores o fazem termina por perpetuar e difundir o preconceito linguístico, pois, ao invés de apenas apresentarem o fenômeno, colocam os traços da variedade popular como "erros" e, além disso, afirmam que os usuários dessa variedade querem dar "aparência de nobreza" ao seu falar, dando origem a fenômenos "grotescos".

Descrever a variedade popular sem conferir-lhe essa conotação pejorativa teria provavelmente estimulado uma reflexão sobre a língua e os elementos que a compõem. Poderia ter sido mais bem trabalhada a noção de "erro", partindo da concepção de adequação linguística. Entende-se que a introdução da definição dessa variedade e a explicitação da perspectiva de erro poderiam nortear a compreensão do professor que lê o guia, levando-o a melhor assimilar a diferença entre as diferentes variedades que compõem a língua italiana e, por conseguinte, a problematizar com maior profundidade essa questão em sua atividade docente.

Assumir uma visão de erro e de variedade que observa e descreve os fenômenos linguísticos ao invés de julgar evitaria o preconceito linguístico e permitiria que o professor tratasse o italiano popular apenas como uma dentre as variedades da língua italiana, as quais constituem um patrimônio cultural precioso, na medida em que são, todas, veículos plenos e perfeitos de comunicação.

Quando foram pesquisadas as características do italiano falado por jovens, partimos da hipótese de que essa variedade poderia estar mais bem representada nos livros por possuir traços um pouco menos estigmatizados do que aqueles da variedade popular.

Para iniciar esse exame, identificamos, antes de tudo, se eram fornecidas informações sobre a idade dos personagens envolvidos nas interações. Como resultado, vimos que são raríssimos os momentos nos quais se vem a conhecer a faixa etária à qual pertencem, e que, normalmente, não é fornecido nenhum tipo de indicação quanto ao perfil do falante, sendo que a voz dos locutores é o único indício com o qual se pode contar.

Entre todos os diálogos dos seis volumes estudados, apenas um foi considerado conversação entre dois adolescentes, tendo em vista que seus personagens tinham voz de pessoas jovens e falavam sobre a insatisfação em assistir à aula de uma professora de história provavelmente em um contexto de sala de aula de ensino médio.

Após encontrar esse diálogo no primeiro volume do manual R! e sabendo que era o único exemplar desse tipo em toda a série, supomos que as formas inseridas refletiriam de alguma maneira o italiano dos jovens e que seriam encontrados ao menos alguns dos critérios de análise

13 “[...] no italiano popular a consecutio temporum, isto é, a concatenação sintática entre os tempos e modos, é frequentemente muito intuitiva e é aqui que se registram os maiores "erros"; quando escrevem, os italianos que normalmente falam italiano popular tendem à hipercorreção, isto é a dar aparência de "nobreza" ao seu escrito - e essa nobreza vem do abuso dos vários tempos do passado, que sobretudo no condicional e no conjuntivo são frequentemente confundidos, com resultados frequentemente grotescos." 
definidos na pesquisa. Contudo, contrariando essa expectativa, a única característica do italiano falado por jovens identificada foi o emprego da expressão "un sacco di compiti" (um monte de tarefas), que, embora seja bastante recorrente em produções linguísticas de jovens, não pode ser associada exclusivamente ao falar dos adolescentes.

Havendo uma única conversa entre adolescentes em todos os volumes dos livros e faltando até mesmo nesse diálogo marcas diastráticas evidentes, era possível prever que encontraríamos poucas ocorrências dos fenômenos buscados nas demais unidades, o que se confirmou, como mostra a tabela a seguir:

Tabela 2: Resultados italiano falado por jovens

\begin{tabular}{|l|c|c|c|c|c|c|}
\hline \multicolumn{1}{|c|}{ Traço investigado } & LD1a & LD1b & LD2 & R!1 & R!2 & R!3 \\
\hline abreviações & 0 & 0 & 0 & 0 & 0 & 0 \\
\hline dialetismos & 0 & 0 & 0 & 0 & 0 & 0 \\
\hline estrangeirismos & 0 & 0 & 1 & 0 & 1 & 0 \\
\hline eufemismos com efeito cômico/irônico & 0 & 0 & 0 & 0 & 0 & 0 \\
\hline expressões cultas usadas informalmente & 0 & 0 & 0 & 0 & 0 & 0 \\
\hline gírias & 0 & 0 & 0 & 0 & 0 & 0 \\
\hline hipérbole & 0 & 0 & 1 & 1 & 2 & 0 \\
\hline turpilóquios & 0 & 0 & 0 & 0 & 1 & 2 \\
\hline metáfora & 0 & 1 & 5 & 0 & 1 & 0 \\
\hline metátese & 0 & 0 & 0 & 0 & 0 & 0 \\
\hline sufixos raros & 0 & 0 & 0 & 0 & 0 & 0 \\
\hline tecnicismos & 0 & 0 & 0 & 0 & 0 & 0 \\
\hline
\end{tabular}

A tabela revela que oito dos doze critérios não foram encontrados em nenhum dos dois manuais e que mesmo aqueles que foram detectados apresentaram uma frequência muito baixa, fazendo-nos concluir que o italiano dos jovens é quase ignorado.

Agrava ainda mais essa situação de exclusão dos traços diastráticos o fato de as metáforas, bem como os estrangeirismos e as hipérboles encontrados, não serem evidenciados em falas de pessoas jovens e tampouco respeitarem o princípio lúdico ao qual se referem Sobrero e Miglietta (2007).

Dado que o princípio lúdico não está presente nos exemplos em que foram encontrados metáforas, hipérboles e estrangeirismos, torna-se difícil considerá-los efetivos traços da variedade falada por jovens. De qualquer maneira, pode-se concluir que eles não foram introduzidos 
com vistas à promoção da sensibilidade sociolinguística, mas sim como construções linguísticas na mesma condição de tantas outras com as quais os estudantes entrarão em contato sem sequer dar-se conta de suas potencialidades e da sua conotação no interior do sistema da língua.

Na direção oposta, os turpilóquios detectados no livro R! preservam o tom lúdico, tanto que os três momentos em que são encontrados são conversas entre amigos, cujas idades não são explicitadas, que falam de assuntos triviais do cotidiano, como quando sair para encontrar amigos ou aonde ir para se divertir. É importante dizer que essas ocorrências não são retomadas no livro, logo, o aluno é impossibilitado de conhecer mais sobre o peso e a avaliação social desse tipo de elemento lexical no interior da comunidade linguística italiana.

Ocupando-nos do tratamento explícito de fenômenos do italiano dos jovens, apenas nas páginas dos livros que compõem $\mathrm{R}$ !2 foram encontrados alguns comentários que diziam respeito a essa variedade. Nos demais volumes de R! e na inteira coleção LD, por outro lado, não foi detectada nenhuma menção nem à variedade, nem aos fenômenos selecionados.

O primeiro trecho no qual se cita a variedade falada por jovens constitui o enunciado de um exercício presente no livro de casa, no qual os autores indicam aos aprendizes o seguinte:

Chiedi al tuo insegnante la trascrizione e leggi il testo della conversazione, riascoltando la registrazione. $\mathrm{Ci}$ sono diverse espressioni tipiche del linguaggio dei giovani. Con un buon dizionario cercane il significato. Attento, però, a volte sono parole o espressioni un po' volgari. Ti consigliamo di non usarle se non sei sicuro di poterlo (e volerlo) fare senza sbagliare registro o offendere qualcuno. (R!2: LE, p. 42) $)^{14}$

Acreditamos que esse tipo de exercício seja importante, mas vale a ressalva de que a abordagem dada pelo livro coloca o aprendiz como único responsável pelo seu desenvolvimento, sendo que não lhe é oferecido nenhum tipo de suporte, além da indicação de usar um "bom dicionário". Não são fornecidas indicações de quais seriam essas "expressões típicas da linguagem dos jovens", tampouco respostas à atividade para que o aprendiz possa confrontar suas respostas com o que era esperado pelos autores do livro. Por conseguinte, sem o respaldo do professor (as atividades do livro de casa são, em geral, realizadas fora da sala de aula) e sem a solução do exercício, cabe ao aprendiz, sozinho, "adivinhar" quais seriam as expressões juvenis contidas na conversa e procurar, também sozinho, a conotação e o sentido a elas atribuídos, tarefa bastante complexa, a nosso ver, quando se pensa que, nesse material, é a primeira vez que o aprendiz entra em contato com essa terminologia e que, portanto, ele não foi preparado para captar as nuances de significado com as quais se defrontará ao longo da execução da atividade.

O segundo comentário também está contido no livro de casa e refere-se à dimensão lexical. Focaliza o termo "sfigato", situando-o como "espressione tipica del linguaggio giovanile e non solo. È sinonimo di 'sfortunato”” (R!2: LE, p. 88) $)^{15}$.

Já o terceiro comentário está no guia do professor e evidencia algumas características do

14 "Peça ao seu professor a transcrição e leia o texto da conversação, escutando novamente a gravação. Existem diversas expressões típicas da linguagem dos jovens. Com um bom dicionário procure seus significados. Mas atenção: às vezes são palavras ou expressões um pouco vulgares. Aconselhamos que não as use se não tem certeza de poder (e de querer) fazê-lo sem errar o registro ou ofender alguém."

15 “expressão típica da língua dos jovens e não só. É sinônimo de 'azarado'." 
italiano dos jovens. Começa-se pelo emprego intenso de superlativos:

L'uso del superlativo sta diffondendosi in maniera esponenziale come effetto dei film, dei giornali, dei mezzi di comunicazione di massa americani. [...] Gli adolescenti e i giovani da sempre tendono a estremizzare, ad accentuare, quindi a servirsi del superlativo; ma gli adolescenti e i giovani d'oggi tendono a incrementare questa loro caratteristica con un abuso di esclamazioni, superlativi, iperboli. (R!2: GP, p. 99) ${ }^{16}$

Nesse trecho os autores afirmam que os jovens "abusam" das exclamações, dos superlativos e das hipérboles. Através dessa fala, dois pontos nos chamam a atenção: em primeiro lugar, a congruência dos livros em relação à bibliografia sociolinguística italiana, que coloca as hipérboles como elemento central da fala dos jovens. Sob outra perspectiva, porém, ao dizerem que os jovens cometem "abusos", expressam um juízo de valor sobre esses usos, indo na contramão do ensino com foco nas variedades linguísticas, posto que, com esse termo pejorativo, evidenciam o preconceito tanto com relação ao emprego dessas formas quanto com a variedade de italiano falada pelos jovens de um modo geral.

$\mathrm{Na}$ análise da terceira variedade - o italiano falado por mulheres - foi possível reiterar a total ausência de discussão sobre as características diastráticas. O quadro gerado foi o seguinte:

Tabela 3: Resultados italiano falado por mulheres

\begin{tabular}{|l|c|c|c|c|c|c|}
\hline \multicolumn{1}{|c|}{ Traço investigado } & LD1a & LD1b & LD2 & R!1 & R!2 & R!3 \\
\hline apelativos afetuosos & 0 & 0 & 0 & 0 & 0 & 0 \\
\hline uso frequente de diminutivos & 1 & 4 & 21 & 1 & 0 & 0 \\
\hline hipérboles & 0 & 0 & 0 & 0 & 0 & 0 \\
\hline uso pouco frequente de palavras tabu & 0 & 0 & 0 & 0 & 0 & 0 \\
\hline
\end{tabular}

Como se vê, quase todos os traços atingem frequência nula independentemente da coleção de livros investigada. Mesmo em diálogos tendencialmente mais informais, nos quais amigas conversam, não foi encontrado nenhum registro de apelativo afetuoso ou de hipérbole.

Dos fenômenos pesquisados, apenas o uso frequente de diminutivos foi constatado em um número relativamente maior de diálogos, porém isso se deu somente no LD volumes $1 \mathrm{~b}$ e 2, enquanto em R! identificamos apenas uma ocorrência de diminutivo usado por falante do sexo feminino.

No LD1 a foi encontrado apenas um exemplo de diminutivo usado por mulheres. No mesmo volume, foram detectadas 5 ocorrências de diminutivos na fala de personagens masculinos, o que mostra que nesse volume esse fator, normalmente associado à variedade feminina, não foi

16 "O uso do superlativo está se difundindo de modo exponencial como efeito de filmes, jornais, meios de comunicação de massa americanos [...] Os adolescentes e os jovens desde sempre tendem a extremar, a acentuar, e, portanto, a servir-se do superlativo; mas os adolescentes e os jovens de hoje tendem a incrementar essa sua característica com um abuso de exclamações, superlativos e hipérboles." 
representado suficientemente. No LD1b, esse cenário se inverte e o número de ocorrências foi de 5, 4 sendo produzidas por personagens femininos e apenas uma por personagem masculino. Finalmente, no LD2, o número aumenta consideravelmente, no total, houve 33 ocorrências, 21 femininas e 12 masculinas.

Embora acreditemos que a presença dessas marcas seja um ponto positivo do manual LD, dado que pode demonstrar certa preocupação em apresentar de forma verossímil a realidade da língua italiana, parece-nos incongruente o fato de que, não obstante esses números, nenhuma menção à conotação do emprego de diminutivos seja feita ao longo das explicações de nenhum dos três volumes do livro. Cremos que se perca a oportunidade de tratar essas questões em sala, enriquecendo as discussões para além da gramática pura e simples e aliando-a a um conhecimento relativo ao peso social das formas linguísticas que empregamos e à função que desempenham na interação.

Quanto ao quarto critério investigado, de acordo com a bibliografia de referência consultada, o falar feminino conteria um número reduzido de palavras tabu, se comparado ao falar masculino. Nos livros didáticos, porém, não houve quase nenhuma ocorrência de palavras tabu, sejam elas enunciadas por homens ou por mulheres, revelando que, no geral, os manuais evitam esse tipo de vocabulário, não o incluindo de forma alguma no insumo oferecido aos aprendizes.

No terceiro volume do R!, foram encontradas apenas duas ocorrências da interjeição "che palle" (que saco!), considerada de uso vulgar ou popular em dicionários eletrônicos italianos (Cf. Hoepli, Sabatini Coletti, Garzanti Linguistica), em uma das ocasiões enunciada por uma personagem feminina e outra por uma personagem masculina. Após essas aparições, contudo, não são feitas observações sobre a conotação dessas expressões, tampouco se reflete sobre uma possível diferença na distribuição desse tipo de expressão em decorrência do gênero e do contexto comunicativo em que se encontram os falantes.

\section{Conclusões}

Na introdução deste artigo, dissemos que nossa proposta era investigar se e como a dimensão diastrática seria contemplada nos livros didáticos de italiano para estrangeiros, tomando como base duas coleções.

Para fornecer respostas a esse questionamento, selecionamos os manuais Linea diretta e Rete! e elaboramos, a partir de bibliografia pertinente, uma lista com 28 critérios capazes de identificar três variedades diastráticas: o italiano popular, o italiano falado por jovens e a variedade falada por mulheres. Em seguida, procedemos à busca dos elementos linguísticos que correspondiam a esses critérios nos diálogos contidos nos manuais e nas explicações oferecidas ao longo de suas páginas.

Após a realização das análises, pudemos constatar que a dimensão diastrática não é totalmente omitida dos livros, pois encontramos alguns dos fenômenos que as marcam nos diálogos e algumas menções explícitas a elas nas atividades dos livros. No entanto, diante dos escassos 
números detectados, fica claro que os resultados estão longe de apontar para uma preocupação real no sentido de incluir a dimensão diastrática como objeto de ensino.

Observamos um panorama no qual os falantes que participam das interações não têm seu perfil descrito, portanto não se sabe se são jovens, adultos, idosos, instruídos ou sem instrução, falantes de dialeto ou não, enfim, não se tem informações suficientes que permitam delinear sua identidade, dificultando a identificação de qual variedade linguística podem estar representando. Além disso, as ocorrências eventualmente verificadas parecem ser frutos do acaso, e não uma consequência do anseio em apresentar a complexidade da língua-alvo. Prova disso é que nas explicações fornecidas a alunos e professores não são praticamente tecidas considerações sobre seus contextos de uso ou sobre sua conotação social.

Nas raras ocasiões em que o livro abre espaço para se referir explicitamente às variedades diastráticas (apenas o livro R!2 o faz), assume-se uma postura preconceituosa em relação a elas, conferindo-lhes juízo de valor e associando-lhes adjetivos pejorativos, como "grotesco", "abusivo", "errado", o que difunde ainda mais a visão de que somente a norma padrão é correta e perpetua o estigma linguístico, nada contribuindo para o amadurecimento sociolinguístico dos aprendizes.

Observando as variedades excluídas dos dois manuais, notamos que elas apresentam um traço em comum: o desprestígio. Nessa ótica, o livro didático, que, como vimos, é o lugar do modelo de perfeição linguística, não pode conter tais construções, pois ensiná-las significaria levar os aprendizes a cometer "erros" na língua-alvo, o que explicaria, mas não justifica, o fato de os fenômenos estigmatizados não terem espaço nos diálogos e nas explicações.

Percebemos que não são oferecidos exemplos suficientes para que os aprendizes entrem em contato com a dimensão diastrática. Nosso auspício é que, cada vez mais, os manuais de línguas estrangeiras incluam as diferentes variedades linguísticas, também para aos diferentes grupos sociais, propiciando maior reflexão sobre o que é uma língua e quais elementos a constituem. Desse modo, os manuais poderão contribuir para promover o desenvolvimento da competência sociolinguística dos aprendizes e, consequentemente, a diminuição do preconceito linguístico tanto na língua materna quanto nas línguas estrangeiras que venham a aprender. 


\section{Referências}

ALFONZETTI, G. Le funzioni del code-switching italiano-dialetto nel discorso dei giovani. Bollettino. Palermo: Centro di Studi filologici e linguistici siciliani, p. 235-264, 2001

BANFI, E. Conoscenza e uso del lessico giovanile a Milano e Trento. In: BANFI, E.; SOBRERO, A. (a cura di). Il linguaggio giovanile degli anni Novanta: regole, invenzioni, gioco. Roma-Bari: Laterza, p. 99-148, 1992.

BANFI,E.; SOBRERO, A. (a cura di). Il linguaggio giovanile degli anni Novanta: regole, invenzioni, gioco. Roma-Bari: Laterza, 1992.

BERRUTO, G. Sociolinguistica dell'italiano contemporaneo. Carocci: Roma, 1987.

. Varietà diamesiche, diastratiche, diafasiche. In: SOBRERO, A. (a cura di). Introduzione all'italiano contemporaneo. Bari: Laterza, 1993.

. Fondamenti di sociolinguistica. Roma-Bari: Laterza, 2003.

. Esiste ancora l'italiano popolare: una rivisitazione. In: DANTER, P.; KONECNY, C. (a cura

di). Dall'architettura della lingua italiana all'architettura dell'Italia. Saggi in omaggio a Heidi SillerRunggaldier. Frankfurt: Lang, p. 277-290, 2014.

COLELLA, G. Come parlano (e scrivono) i giovani. In: DARDANO, M.; FRENGUELLI, G. (a cura

di) L'italiano di oggi: fenomeni, problemi, prospettive. Roma: Aracne, p. 189-212, 2008.

CONFORTI, C.; CUSIMANO, L. Linea Diretta Nuovo:corso di italiano per principianti. Perugia: Guerra, 2005.

CORACINI, M. J. R. F. (org.). Interpretação, autoria e legitimação do livro didático:língua materna e língua estrangeira. Campinas, SP: Pontes, 1999.

CORTELAZZO, M. Lineamenti di italiano popolare. In: Cortelazzo, M. Avviamento critico allo studio della dialettologia italiana. Pisa: Pacini, 1972.

CORTELAZZO, M. Il parlato giovanile: In: SERIANNI, L.; TRIFONE, P. (a cura di), Storia della lingua italiana, Volume II:scritto e parlato. Torino: Einaudi, p. 291-317, 1994.

COVERI, L.; BENUCCI, A.; DIADORI, P. Le varietà dell'italiano: manuale di sociolinguistica italiana:con documenti e verifiche. Siena: Università per stranieri di Siena/Roma: Bonacci, 1998.

D'ACHILLE, P. L'italiano contemporaneo. Bologna: Il Mulino, 2006.

DE MAURO, T. "Per lo studio dell'italiano popolare unitario". Nota linguistica a Annabella Rossi: Lettere da una tarantata. Bari: De Donato, p. 43-75, 1970.

LAKOFF, R. Language and the woman's place. New York: Harper and Row, 1975.

LUNATI, BALTHAZAR, FREITAS. Il ruolo dei dialetti nelle politiche per l'educazione linguística degli italiani dall'unità ad oggi. Revista de Italianística, n. 30, p. 125-145, 2015.

MARANO, L. Lingua e dialetto in due gruppi giovanili napoletani. Primi risultati di un'indagine in corso. In: MARCATO, G. (a cura di). Tra lingua e dialetto. Atti del convegno internazionale di studi "Tra Lingua e dialetto". Padova: Unipress, p. 73-78, 2010.

MEZZADRI, M.; BALBONI, P. E. Rete!: corso multimediale di italiano per stranieri. Perugia: Guerra Edizioni, 2000.

MOCCIARO, A. Alcune considerazioni sull' italiano popolare (con particolare riferimento all' italiano popolare di Sicilia). In: Gruppo di ricerca dell'Atlante Linguistico della Sicilia (a cura di). Per i linguisti del nuovo millennio. Scritti in onore di Giovanni Ruffino. Palermo: Sellerio, p. 322-326, 2011.

MONTUORI, F. Recensione a Forme della comunicazione giovanile. Lingua italiana d'oggi, v. 3, p. 435-448, 2006. 
RADTKE, E. Varietà giovanili. In: SOBRERO, A. (a cura di). Introduzione all'italiano contemporaneo: la variazione e gli usi, Roma-Bari: Laterza, p. 191-235, 1993.

. Nuovi sviluppi nella comunicazione giovanile. In: FUSCO, F.; MARCATO, C. (a cura di). Forme della comunicazione giovanile. Roma: Il Calamo, p. 283-296, 2005.

SANTIPOLO, M. Dalla sociolinguistica alla glottodidattica. UTET Università: Torino, 2002.

SOBRERO, A. A.; MIGLIETTA, A. Introduzione alla linguistica italiana. 2. ed. Bari: Laterza, 2007. Per un approccio varietistico all'insegnamento dell'italiano a stranieri. In: Italiano LinguaDue, v. 3, n. 1, 2011, p. 233-260. (primeira parte)

v. 3, n. 2, 2011, p. 243-257. (segunda parte)

SPITZER, L. Lettere di prigionieri di guerra italiani 1915-1918. Torino: Boringhieri, 1922.

TORQUATO, C. P. Le varietà del repertorio linguistico e l'insegnamento dell'italiano come lingua straniera. Revista de Italianística. n. 21-22, p. 149-160, 2011.

Recebido em: 12/12/2019

Aprovado em: 28/12/2019 